\title{
Best practices for economic development organizations
}

\author{
John Barnard, Ec.D.
}

\begin{abstract}
In the past few years there has been a resurgence and emphasis on 'Best Practices' in commerce. The business section in any bookstore is loaded with volumes extolling us to seek even higher levels of sophistication and excellence in our business functions. As economic developers, we are challenged to respond to the demands of socioeconomic shifts driven by technology, globalization and governance. This paper is, in part, an account of how one economic development organization, the Leduc/Nisku Economic Development Authority (EDA), responded to these shifts and how 'Best Practices' were employed to accomplish the results targeted. In the process it will describe how a paradigm shift took place, as 'Best Practices' became the actual program rather than the means of enhancing existing programs. The examples will show the process, what can be achieved and the importance of working with the will and spirit of a community.
\end{abstract}

Keywords: best practice, corporate culture, Leduc/Nisku Economic Development Authority (EDA)

\section{Introduction}

'Best Practices' have been around for a long time. Perhaps the earliest recorded were ten suggestions listed by a gentleman named Moses on Mount Sinai about two thousand years ago. With varying degrees of success, we all try to lead our lives based on a set of values we each hold dear. These values determine the way we choose to conduct our lives and the way in which we wish to be treated. Not surprisingly, we tend to apply the same standards we adopt for our private lives to our corporate existence. So why is it that there has been such a resurgence and emphasis on 'Best Practices' in commerce over the past few years? The business section in any bookstore is loaded with volumes extolling us to seek even higher levels of sophistication and excellence in our business functions. Lance H. K. Secretan tells us that values must replace rules.

"Rules describe what cannot be done, but the soul yearns to be enabled, to know what can be done". 1

As individuals, corporations and communities we are urged to adopt programs from expanding our minds to building better relationships.

\footnotetext{
${ }^{1}$ Lanee H.K. Secretan, 1996.
} 


\section{Change}

"Today the rate of change has reached a point where it is questionable whether the environment can sustain it" (Burke, 1978)". ${ }^{2}$

Increasingly, communities are finding it difficult to adjust, let alone plan, to meet the new demands that are being placed upon them. The structured approach to urban planning, based on a tradition of geographical planning, seems inadequate to address today's needs. As economic developers, we are challenged to respond to the demands of socioeconomic shifts driven by technology, globalization and governance.

"Organizations are realizing that they will not survive if they do not change. The result of this need to change is a push toward continuous learning for continuous improvement". 3

This paper is, in part, an account of how one economic development organization, the Leduc/Nisku Economic Development Authority (EDA), responded to these shifts and how 'Best Practices' were employed to accomplish the results targeted. In the process it will describe how a paradigm shift took place, as 'Best Practices' became the actual program rather than the means of enhancing existing programs. The examples will show the process, what can be achieved and the importance of working with the will and spirit of a community.

"By focusing attention on a vision, the extraordinary manager operates on the emotional and spiritual resources of the organization, on its values, commitment and aspirations. The ordinary manager, by contrast, operates on the physical resources of the organization, on its capital, human skills, raw materials and technology". 4

During the process, the tremendous power that can be generated by harnessing and focusing the latent human energy that exists in every community was experienced.

The approach was an evolutionary development, achieved by understanding the socioeconomic shifts in the community, working with a high-energy team capable of 'thinking out of the box' and building upon their strengths and successes.

"High-performing organizations create a vision that challenges members by encouraging them to go beyond familiar ways of thinking; they provoke members to

\footnotetext{
${ }^{2}$ James Burke, 1978.

${ }^{3}$ Karen E. Watkins and Victoria J. Marsick, 1993.

${ }^{4}$ Warren Bennis, Jagdish Parikh and Ronnie Lessem, 1994.
} 
stretch beyond what has seemed to be reasonable limits, to redefine the boundaries of what they experience as constraining". 5

\section{Best practices}

The label 'Best Practices' has been tied to almost every function you can imagine. What is interesting is that it tends to be sector specific and has a different connotation for each sector. For example, the label is most widely used in the agricultural sector, where it relates primarily to conservation and environmental practices. In the service sector the inference is directed towards customer service. In business terms it is most often used to indicate a level of efficiency or quality control.

"Best Practices are the best ways to perform a business process" 6

In other sectors the term is applied to safety, financial responsibility, education and training. In all these examples the application of the term is focused on just one program or aspect of the sector.

In economic development the approach has not been much different. Perhaps the first reference to 'Good Practices' was at the Second European Conference on Sustainable Cities and Towns in Lisbon, Portugal, in October 1996. Here again, it is associated with benchmarking, often related to either job creation or municipal tax generation; both standards of measurement for economic development more suited to the old industrial development era. At the European Association of Development Agencies (EURADA) Brussels Conference in 1998, all the examples provided were of specific economic development programs, which were offered as 'Best Practices'. At the conference it was difficult to develop criteria to judge what constituted 'Best Practices' or what was simply a good or excellent program. The web site of the United Kingdom Department of Trade and Industry, http://www.dti.gov.uk/mbp/ is one of the more sophisticated economic development sites extolling the virtues of 'Best Practices'. However, once again, the focus of the application is on business practices. While the site promotes the harnessing of the combined intellectual power within a company, it makes no effort to develop this on a consortium, sector or regional basis. The checklist it provides covers sound business practices, which have been recommended by business consultants for many years.

None of the examples cited took a holistic approach in which 'Best Practices' was adopted for greatest benefit to the company, its customers, suppliers, employees and community. The

\footnotetext{
${ }^{5}$ Frank J. Barrett, 1995.

${ }^{6}$ Arthur Andersen, Simon and Schuster, 1998
} 
emphasis was on making existing practices better, rather than on innovation and creativity. Professional, moral and ethical considerations rarely featured in the motivation for the practice.

\section{Kyoryoku kai}

An example of a form of 'Best Practices', which a company employed, then shared on a community basis, comes from Wales. A high technology Japanese manufacturing company was attracted to invest in the construction of a new factory. The company practiced a management style known as Kyoryoku Kai, in which management is facilitated by the creation of worker/staff/management cells. The Welsh Development Agency (WDA), based in Cardiff, recognized the advantage that this style of management gave the Japanese company and asked if they were prepared to share the techniques. The result was the construction, by the WDA and the Japanese Company, of a training institute where the Kyoryoku Kai technique was offered to all the companies in South Wales; thereby raising the corporate management skills of the whole business sector. This example is closer to a community approach, but fails to take it beyond the actual management of individual businesses.

\section{Dynamics of trade}

As technology alters the way in which we do business, it is understanding the shift in the dynamics of trade that makes economic developers appreciate the role they have to play in working with business. In the past, trade and commerce were carried out based on personal relationships, often consummated with a handshake. Today, a growing volume of trade and commerce takes place electronically at lightning speed between vendors and purchasers in every corner of the globe. In many instances it has become totally impersonal and rarely is there the opportunity to trade on a relationship built upon years of personal contact. The legal contract has replaced the traditional handshake and given word. In many cases a climate has been created in which emphasis is placed solely on meeting the requirements of the contract, with no time allowed for personal service. Change, driven by technology, has invaded every facet of business and industry, altering the way in which we manage our operations and conduct ourselves.

This shift in the dynamics of trade has spread the obligation to provide ethical and moral commitment from the individual to the corporation. 'Best Practices' is more than the efficiency of systems and processes. It is the combination of ethics and the search for excellence in every undertaking; in other words it is a corporate attitude.

If creating a corporate attitude is advantageous for business, then why not use the same logic and apply it to the community as a whole. Instituting 'Best Practices' demands total commitment and an attitude adjustment rather than simply adopting a new corporate policy. 
It is the way people choose to conduct their business, the service they provide and the manner in which they treat each other. It is the difference between providing good service and providing exceptional service. It is the means by which they move to a new higher level of operation. The adoption of 'Best Practices' is not confined to the corporate arena; it is equally applicable to all individuals, businesses and communities. This was not lost on Frank Ogden in 'The Last Book You Will Ever Read', who counseled people to always, "Hire on attitude alone".

It should not be surprising that economic development has a vested interest in encouraging 'Best Practices'. Every community is a reflection of its economic, social and cultural spirit. No one knows better than the economic developer that communities, which project a healthy, dynamic and vibrant economic and social environment, have a clear competitive edge. Making a commitment to 'Best Practices' should not be undertaken lightly, for it will impact every function of business and organization. It calls for leadership, vision, dedication and commitment to a constant effort, something which Mother Teresa herself represented and articulated in the following words:

"To keep the lamp burning we have to put oil in it".

\section{Driving force}

The driving force for a 'Best Practices' approach may come from different sources. For some it may be embodied in their corporate mission statement or mandate. These statements can often include direction on how to treat individuals, communities and corporations. It may be a code of ethics promoted by an existing business or professional group such as Rotary International; alternatively, it may be a spontaneous individual desire to serve customers better, be more competitive or bring a higher level of professionalism to all that they do. Of course it is possible to adopt a 'Best Practices' approach to one segment of a company's operations. For example, the company may have a very creative and efficient design department capable of producing the most innovative designs in the industry. Unfortunately, all this is of little use if the other operations of the company do not measure up to the same standard. This approach cannot sustain itself if the cross motivation between operations does not occur. Eventually, the 'Best Practices' function will be dragged down to the level of the other operations. For success, 'Best Practices' must be incorporated across the whole corporate structure in order that it may stimulate even the weakest functions to seek improvement.

By now it will be obvious that 'Best Practices' is far from an exact science. There are many gray areas, especially in the degree to which competition becomes the driving force. Dennis Conner, Americas Cup winner, is widely admired for his success; however his whole approach is to win,

\footnotetext{
${ }^{7}$ Frank Ogden, 1993.
} 
almost regardless of cost. There are no compromises; the selection of crew, training, financing and use of technology are focused toward that single goal, winning. 'Best Practices' is more holistic in concept, seeking a 'win-win' option, in which the greatest shared benefit can be generated. It is about principles.

'Best Practices' creates advantages for individuals, the corporation and its suppliers and customers; however, care must be taken to keep a balance between the interests of each of these parties. The individual must be given the opportunity to grow and be rewarded for increased productivity and value to the organization. The corporation must make the commitment to stand by its stated policies and support 'Best Practices' initiatives throughout the entire organization. It must respond to the demands for change and investment in resources, especially technology. Suppliers and customers will respond to greater efficiencies and productivity by placing more business and promoting the corporation through word of mouth.

The role of management is to maintain the motivation of the entire work force and to ensure that neither narrow internal or external benefits become focused as the goal. These benefits will accrue naturally as the product of a holistic approach to 'Best Practices', where one strives for excellence in every facet of the organization.

\section{LEDUC/NISKU}

The Leduc/Nisku Economic Development Authority (EDA) is an example of the adoption of 'Best Practices' to enhance community economic development services. Leduc is a small city of 16,000 , situated in the center of the province of Alberta in western Canada, just south of the provincial capital of Edmonton. It is the historic site of Leduc No. 1, the first commercial oil well discovered in 1947. Around this find grew up industry to meet the needs of the energy sector in the province and Nisku became western Canada's largest industrial park. In 1991, Leduc/Nisku was no different from many other communities with a boom and bust economy, vulnerable to the cycles of the energy sector and dependent upon a regional market. To compound the challenge, there was distrust between the two municipalities following an unsuccessful attempt by the city of Edmonton to annex the Nisku Business Park.

\section{The partnership concept}

In 1992 Leduc/Nisku faced a critical transition in the delivery of economic development services. A conventional structure, consisting of a board of directors and two staff members, was responsible for developing and implementing programs funded by municipal taxes. Impact was limited by the time available from the staff and the dollars in the budget. A new strategy to build a stable and sustainable economy for the community called for diversification of industrial 
sectors and a move into international markets. Fritjof Capra, author of The Tao of Physics, defines sustainable communities as those that,

"exist in social and cultural environments in which we can satisfy our needs and aspirations without diminishing the chances of future generations". ${ }^{8}$

Perhaps one of the greatest challenges faced was raising the delivery of economic development services to a 'Best Practices' level. To reach a level of activity required by the socioeconomic conditions in the community at the time, the economic development function had to go beyond the human and financial resources provided through the conventional municipal structure. The EDA understood that to achieve its goals it would have to use creativity and innovation to move out of the conventional economic development 'box'.

"...human beings are designing beings. They create, store, and retrieve designs that advise them how to act if they are to achieve their intentions and act consistently with their governing values. These designs, or theories of action, are the key to understanding human action". 9

In Leduc/Nisku it was necessary to learn a whole new dynamic of working with the community, its people and organizations, while maintaining a full range of conventional economic development services. A full time office continued to provide a resource for business and industry, counselling and business plan services, demographic and statistical information, forecasts for councils, marketing, promotion, business retention and attraction strategies. The transformation required was more than a quantum leap. As a measure of the dimension of the change, in marketing alone the EDA moved from three local trade shows per year in 1993 to 56 international events in 1998. In terms of regionalization, the change went from serving two municipalities to providing economic development services to seven communities. Not only was the magnitude of the change massive, the rate at which it took place was equivalent to squaring the level of all activities every quarter.

The concept adopted was built around the creation of the Leduc/Nisku Economic Partnership. The process was to use the resources and energy of the community as a whole to focus on socioeconomic issues. This energy exists in every community; unfortunately, in many cases it is dissipated - by being pulled in every direction. It was felt that if the EDA could bring people together, line them up and have them all pull on a single rope in one direction, the community could achieve anything it wished. This innovative approach to the delivery of economic development services responded to the demands of globalization, the opportunities afforded by

\footnotetext{
${ }^{8}$ Fritjof Capra, 1992.
}

${ }^{9}$ Chris Argyris, 1993. 
new technologies and speeded the transition in governance to community driven or social learning as described by Professor Gilles Paquet, in The Policy Process: Challenges and Responses (1998).

Formed in 1992, the Partnership brought community leaders and business people together for a monthly breakfast at which local economic issues were discussed. These breakfasts have become the expression of this energy and have grown to an average attendance of over 300 . It is from this resource that teams of volunteers are recruited.

"People learn best when they tackle real problems together in small teams of peers, none of whom is the expert. They take action and think about results, using others in the group to see the situation in new ways". 10

Seven teams, working on specific economic development issues, provide the EDA with the equivalent of a staff of 135, five of whom get paid. In 1998 a total of 25,000 hours of volunteer time was logged for economic development, facilitated by the staff of the EDA. This resource generated the energy and momentum to undertake a scale of activities far beyond the core resources of the EDA.

The strength of the Partnership has been that it is unstructured, with participation based solely on interest. There is no membership fee, just lots of recognition for any voluntary contribution made. This approach has given a wide cross section of the community much greater input into local government through recommendations generated by the teams. This initiative has taken economic development out of the boardroom and put it firmly back into the community, where it has become truly community focused and community driven. The role of the EDA has changed to servicing and facilitating this Partnership, its programs and volunteers.

"This is the dream - that we can design and create organizations which are capable of adapting, changing, developing and transforming themselves in response to the needs, wishes and aspirations of people, inside and outside". 11

In 1992 the EDA introduced an Ambassador program to recognize the contribution made by volunteers for the community. Nominated by a colleague, anyone who boosts the community is eligible to become an 'Leduc Nisku Ambassador'. Installation is done publicly at a Partnership breakfast, where Ambassadors are introduced and receive a certificate signed by both Mayor and Reeve. In addition, personalized pins and business cards, luggage tags and a license plate for their car are provided. This simple program enables the community to thank citizens who may

\footnotetext{
${ }^{10}$ Karen E. Watkins and Victoria J. Marsick, 1993.

${ }^{11}$ Mike Pedlar, 1991.
} 
otherwise be overlooked and is especially useful for recognizing foreign visitors and other dignitaries. Currently, Leduc/ Nisku has over 600 Ambassadors, essentially a huge unpaid sales force promoting the community worldwide. Both the Partnership concept and the Ambassador program have been recognized internationally for their innovation and excellence in delivering community economic development services.

\section{How it began}

The application of a 'Best Practices' approach grew as the activity and success of the Partnership grew. In the example of the EDA, it was the collective initiative of the staff that set goals for themselves and the organization. They demanded that the highest level of customer service be provided in the most professional manner. Two events signaled the first conscious move towards recognition that 'Best Practices' were, in fact, being adopted. From time to time the EDA had entered various competitions for marketing and economic development programs. A casual remark one day, suggested that it would do no harm to flaunt the random successes and hang the plaques and certificates on the office wall. Thus was born 'The EDA Wall', which currently is home to 59 different awards. It was not long before the staff coined the slogan that "you cannot leave home without returning with an award"!

The 'Wall' stimulates a spirit of competitiveness to be the best and involves everyone in the office in the process. All take ownership of the results displayed and its impact is evident on visitors and, indeed, anyone who enters the office. The message is unmistakable; this is an organization with which to be reckoned!

The second, and at the time unrelated action, was the initiative to set a standard for correspondence and journalism, which would ensure that every communication that left the office conformed to a standard format, was error free and grammatically correct. Perhaps no other initiative has laid such an essential foundation for 'Best Practices'.

'Best Practices' was applied to all the economic development programs, partnerships and every other function of the organization. Every issue was challenged for innovation, efficiency and effectiveness. This attitude towards excellence became infectious, influencing the board, Partnership and, eventually, the whole community. Through participation in professional economic development organizations and events, it provided the means by which the EDA was judged and set a benchmark for other economic development organizations interested in implementing similar initiatives. 


\section{Networks}

The individual, corporate and community networks and partnerships an economic developer builds and maintains are the very lifeblood of a professional economic development office. They are the means by which the intelligence is generated that enables the economic developer to plan and manage a community's economy. The effectiveness of the economic developer's efforts is in direct proportion to the quality and use to which these networks are put to use. Through them the developer learns, prospects, partners, promotes and prospers. This is a key economic development function, which must have outstanding expertise, technology, innovation and creativity, to support all other economic development activities. By applying a 'Best Practices' approach to its database and network, the EDA was able to deliver a new level of community economic development.

"The old metaphor was one of a machine, of components that operate in a linear fashion and outcomes that are predictable. The new metaphor is one of a living organism - extremely complex, unpredictable and interconnected to other organisms". ${ }^{12}$

From a pocket full of other people's business cards, a rolodex, a highlighted business directory or a computer database, we have all managed our own special forms of networks. The system or software on which a network is built may vary; however, it is the application of that information which makes it come alive. Just as a pile of sheet music is silent until the maestro turns it into a symphony, a database is just a list until it is brought alive as a network. Today's technology enables massive lists to be generated containing files and files of information. It is the transformation of this cold hard information into knowledge and attention that enables it to be taken from a basic directory to a dynamic and interactive network.

Central to any economic development activity is knowledge, based on reliable information. The first component of any network is the quality of the information, which must be current and accurate. Working with a local software company, database software specifically for economic development networks was developed by the EDA. Unique to this database is the interactive capability, whereby individuals and companies are responsible for updating their own information online. This ensures that information is kept current and reduces the time needed to maintain the information required on the 1,900 companies, over 1,000 individuals and 50 organizations contained in the database. It provides over 20 options to monitor business and industry, providing the statistical information required. These options include employment, markets served, ISO certification, products, services and technologies. The information is readily

\footnotetext{
${ }^{12}$ Jerold Apps, 1994.
} 
available through the web site Leduc-Nisku.ab.ca and is the foundation for communication with many individuals, groups and sectors within the region. The database is capable of identifying and selecting individuals or groups, together with their preferred means of contact.

An active network is one in which each contact is touched on a regular basis, perhaps at least eleven times every eighteen months. In Leduc/Nisku a special effort is made to ensure that every business is contacted, by phone, mail, fax, e-mail or visit, on average of once each month. It is the means of correspondence with international partners and the prime resource which fuels all economic development activities. One does not have to look far for other examples of businesses, which keep their networks alive. Retailers, especially auto dealers, insurance and other professional service providers seldom miss an opportunity to remind contacts that they are all members of their network family. A good example of this is 'The Readers Digest', which holds its subscribers in a constant dialogue through competitions, special offers and programs. A 'Best Practices' database enables this to be accomplished and, more importantly, to be used to generate knowledge about a community not otherwise obtainable.

It is innovation in using the knowledge provided by this database that lifts it to the level of a 'Best Practices' network. This is the magic which enables static information to be transformed into dynamic intelligence. The puzzle, then, is why so few economic development organizations have made the conscious effort to apply 'Best Practices' to the tools, which are the foundation of their success.

\section{Knowledge}

"Living, learning companies stand a better chance of surviving and evolving in a world they do not control. They make sense, especially because success now depends on mobilizing as much of the intelligence at a company's disposal as possible". ${ }^{13}$

The creation of a business directory enabled the EDA, for the first time, to understand the collective resources in its community. Through analysis it was possible to define total resources such as manufacturing and production capacity, laboratory and testing capabilities, the range of products, services and technologies. It provided the ability to monitor and track trends, measure growth and generate demographic information on the business community. This knowledge enabled a move forward from promoting individual companies and products, to marketing the collective strength and productivity of all its companies. In this manner an intellectual property for the business community was created providing a resource of incredible power for management, marketing, forecasting, communications and networking.

\footnotetext{
${ }^{13}$ Arie de Geus, 1997.
} 
Using this intellectual property (knowledge), a support package was developed. This package provided education, counselling, training, export readiness, ISO certification and international marketing for the collective business community. The products, services and technologies of all companies in the region were listed on a single floppy disk providing easy access to the information required. This use of technology, to move from static hard copy to dynamic electronic information, not only provided the EDA with more useful information, it also cut the cost of delivering that information. Since it was first introduced in 1990 the disk has been sent around the world to Canadian trade officers, purchasing departments of major corporations and anyone who asks for a copy. At trade shows, on trade missions and at every opportunity the disk is distributed at no cost. In 1994 the full directory was added to the EDA web site (www.leducnisku.ab.ca) and is available globally via the Internet. This site currently receives 25,000 'hits' per month, creating another interactive component to the network and stimulating the economy at the same time.

\section{Marketing}

Promotion of communities is fundamental for most economic development functions. The EDA wanted to be sure that its marketing strategy was built on the collective productivity of its businesses and industries, as well as its physical environment. This strategy was designed to be unrestricted by the size of the community or conventional budgets, to provide stable and sustainable economic growth. A community marketing team invested over 300 hours of volunteer time to evaluate 19 different sectors and many international markets. The resulting strategy focused on three markets and three industrial sectors. The markets were South America, Asia and Europe; the sectors were energy, environmental technologies and advanced technologies /communications. This ambitious strategy was implemented in 1993 by attracting resources from all stakeholders and has been built upon ever since. In 1998 the EDA participated in no less than 56 international trade shows, trade missions and conferences, providing massive exposure for both business and community. This strategy has been in place over the past seven years and continues to be the driving force for economic development in the community. Any inquiries received are immediately routed to the companies best suited to respond. Currently, $50 \%$ of the companies in Nisku Business Park are working in export markets. The following statistics illustrate the growth in penetration in out of province markets:

In 1995 Leduc/Nisku had 102 companies doing business in the United States; in 1999 it had 233. In 1995 there were 45 companies doing business in South America; in 1999 there were 104. In 1995 there were 22 companies doing business in the Middle East; in 1999 there were 85 . In 1995 there were 39 companies doing business in Russia; in 1999 there were 91. Companies doing business in Western Europe have gone from 18 to 89, Australia from 18 to 81, China from 29 to 
81, India from 18 to 78, Japan from 19 to 77 , Mexico from 20 to 78 and the Caribbean from 17 to 73 .

Part of the success for the rapid growth in market penetration is the ability of the EDA to market flexible networks, clustering two or more companies to address specific projects. This is especially important in both the energy and environmental sectors, where projects call for a wide variety of expertise. Using this technique, the EDA aggressively set out to market the community as a center of excellence for these sectors.

This marketing strategy has achieved its objective of eliminating economic dependence upon one industrial sector and one market. The marketing program moved from passive community brochure distribution to a dynamic active marketing of the collective resources of all business and industry. It has built a strong and stable regional economy and is an example of how 'Best Practices' was employed to maximize marketing efforts out of all proportion to the size of community and the resources available.

\section{Technology}

Technology has not escaped the EDA's drive towards 'Best Practices'. Equipment in the office was upgraded to provide the most efficient electronic systems, resulting in a compact local area network powered by its own server and providing each workstation with full computer and Internet functions. Leduc was the first community in Canada to build its own community Internet server in 1994, providing both private and public sectors with access to the Internet. Technology was employed to help achieve greater efficiency and enable more to be done, faster, with fewer resources. Recently linked via microwave at 2.5 megabytes per second into a fiber optic network, the system has the capability for video conferencing and ultra high-speed communications. Through technology it is possible to interact with other more sophisticated knowledge based economies and to create the economic strength from which to move forward.

\section{Success}

Adopting a policy of always striving for excellence makes what we do a work in progress; the task is never finished. In the same way, evaluation of results is an ongoing process. The EDA built in a quantitative measurement process to monitor the creation of new jobs, value of new construction, penetration of new markets and number of new businesses. Valuable as this is, it is still only part of the picture. More important is the development of the soft infrastructure. The level of volunteer participation, the degree of cooperation between community organizations, the spirit of the community and the attitude towards creating a better future are the components which set this community apart. 
The EDA network, or 'family', for that is how it functions, has grown stronger and more powerful. It is the vehicle, which creates prosperity, positions the community and sets the standard for all 'Best Practices'. In just the same way that negativity can spread like cancer, 'Best Practices' can infect a whole community for the common good; limited only by the vision and energy of its leaders. There is no more appropriate function for the professional economic developer than to respond to the challenge and set the standard for others to follow.

In its current evolution, the Leduc/Nisku EDA has expanded to provide economic development services to seven municipalities, combining their collective strength to create 'Alberta's International Region'. The advantages provided to business and industry are now spread even wider and an expanded intellectual property provides even greater opportunities.

"Learning in the learning organization is highly social. People learn as they work together toward the achievement of clear goals that they help to create. Individuals help other individuals learn". ${ }^{14}$

Special efforts are made to maintain an ongoing and high level of staff education through the University of Waterloo, professional organizations and other formal economic development organizations. The EDA is committed to having two qualified economic developers on staff. Programs are also instituted for volunteer board members. Success is the direct result of a board of directors who run with the program, and a core staff of four exceptional people who provide the professionalism, energy and creativity to achieve outstanding results.

\section{Recognition}

So how does one recognize 'Best Practices', especially in economic development, when any evaluation of performance has always been an area of contention? How do we take it out of the merely subjective evaluation?

The Leduc/Nisku EDA wanted to demonstrate to its own community that the services, processes, programs and policies it was implementing were the best that they could be. It also wanted to create a role model for businesses and other communities. It understood that success that could be measured, together with evaluation by a qualified third party, were the criteria, which would confirm it was, indeed, using 'Best Practices'. Accordingly, the EDA applied for and received full accreditation from the American Economic Development Council (AEDC), in 1997. This audit is designed specifically for economic development organizations and examines all aspects of the organization under sixteen different criteria. It covers staff, office procedures, board,

\footnotetext{
${ }^{14}$ Karen E. Watkins and Victoria J. Marsick, 1993.
} 
programs, partnership and teams. Examples of work going back to the inception of the organization, including mission and mandate, structure, policies and procedures are required. Copies of strategies, with a full range of support material, press clippings over the past twelve months, samples of marketing materials, resumes of all staff, financial statements and budgets must be submitted. A full inventory of activities, programs, trade shows and trade missions, together with photographs of special events must be provided. Specifications for computer networks, together with software and databases, result in a large box of corporate history and support material, which becomes the application for accreditation. A personal audit follows acceptance of the material submitted.

Two past Presidents of AEDC arrange to visit the offices of the organization to conduct their personal audit. An agenda is supplied covering visits and stakeholder interviews they wish to conduct in the community. These visits include the organization, board, City Council, Chambers of Commerce and other business related organizations. Meetings are arranged with recently located business people, financial institutions, media, real estate, government, volunteers and, of course, all staff members.

The report that follows these visits is most useful in identifying what is being done right and where there is need for improvement. Projects are traced by evaluating how strategies are developed, budgets raised to support them, implementation and the results achieved. This provides an awareness of the need to guard against projects, which are ill conceived, poorly funded, inadequately carried out with corresponding lack of results. Through the personal audit, the EDA was able to share the 'Leduc/Nisku Experience', the energy and 'Best Practices' attitude that it brings to everything it undertakes.

Currently, the Leduc/Nisku EDA is the only economic development organization in Canada to have received this accreditation. The evaluation by a third party, a professional organization, together with the tangible results achieved, confirms that the EDA is indeed using 'Best Practices'.

The example of accreditation was used to demonstrate the value of seeking independent recognition such as ISO 9000 or equivalent certification to the business community. This international quality control program is an excellent way for businesses to check how they measure up against recognized standards. Accreditation or certification is especially important for working in international markets. In fact, in some areas it is virtually impossible to do business without it. 


\section{Yes we can}

As recognition for the EDA and its programs grew, the success became infectious and reached into the community. Prior to 1990, Leduc's City Planning Department had a reputation for being difficult to work with and developers did not look kindly upon the city as a place in which to invest and do business. The Mayor and council recognized the problem, made changes and, most importantly, launched a 'Yes We Can' campaign. Banners were made, notices posted, staff trained. From then on it was 'Yes We Can' as opposed to 'No You Cannot'! Slowly, other organizations in the community, such as the Chamber of Commerce and Business Revitalization Zone, adopted a new confidence and optimism for the future. Through the Partnership, the EDA was able to touch a wide circle of people, businesses and groups in the community, providing motivation, leadership and direction.

"The greatest leaders and statesmen in history have not been problem solvers. They have been builders. They have been creators. Even in time of great conflict, such as war and depression, they have taken action to bring into being the society they envisioned". 15

\section{Audit}

In the process of applying 'Best Practices' to its own actions, the EDA has always tried to set the example and encourage business to be the best that it can be. One of the tools used is a series of steps, from self-evaluation through to an independent audit, which provides a means to improve business retention activities. Key questions to evaluate the employment of 'Best Practices' are:

Step 1

Commitment

Do you have a philosophy, mission or mandate statement that identifies your commitment to employing only 'Best Practices'?

Driver

Can you identify the individual or team who champions your quest for 'Best Practices'? Who sets the example and who is responsible for providing recognition to those who embrace 'Best Practices'?

\footnotetext{
${ }^{15}$ Robert Fritz, 1989.
} 


\section{Resources}

Have you, or your organization, made the commitment in time and resources to adopt 'Best Practices'? Are you open to seeking change, to breaking the mold, to working smarter and investing in technology for greater efficiency?

\section{Professionalism}

Is your organization committed to ongoing education and training for all your personnel? Do you encourage and recognize the highest standards in all trades, professions and volunteers?

\section{Comprehensive}

Can you identify all the functions of your business, its processes and strategies that would benefit from adopting 'Best Practices'? Are there existing complementary quality control programs available for these functions?

\section{Competition}

From simple 'employee of the month' to international competition, have you initiated competition, both internally and externally, and celebrated your success? When did you last receive a written compliment for your service?

\section{Monitor}

'Best Practices' will impact every one and every sector of your organization. Are you monitoring your progress and communicating your success, both internally and externally? Have you ensured that the pride in your success becomes infectious and not only permeates your employees, but spreads beyond to your suppliers and customers?

\section{Step 2}

The EDA was fortunate to be able to partner with the provincial government to offer local businesses a free confidential independent evaluation for business performance. This evaluation is carried out by professional business counsellors and looks at all aspects of a business. Where appropriate, recommendations are made to improve specific functions. This evaluation measures the performance of the business and provides confirmation that there is a healthy business upon which to build. 'Best Practices' enhances good business practices; it cannot provide a substitute for poor business practices.

In the event that a similar program is not available, it is possible to call in an independent audit or carry out a more detailed self-audit. This involves evaluating and tracing programs, reviewing how they were conceived, financed, implemented and if they came in on time, under budget and produced the results expected. The corporate history, business plan, programs and strategies are 
all reviewed. The financial performance of the company is evaluated, using 20 basic business ratios and staff records are reviewed for turnover, productivity and personal growth. 'Best Practices' is not just about improving the bottom line; it is about the way in which business is conducted.

\section{Step 3}

Having completed the first steps, it is time to move forward to other options. One is to make an application for ISO Certification. The second, to seek accreditation or an equivalent recognition, depending upon the profession or business. These are not inexpensive exercises, so the greater the preparation, the better. Either route will ensure that there is an on-going program for improvement to ensure that the highest standards are always maintained.

\section{Best practices for economic development}

In looking back at the Leduc/Nisku experience, the following criteria may be used to understand what evolved into 'Best Practices' for economic development:

1. 'Best Practices' is an evolutionary process. Practices of ten years ago are as obsolete as practices of the 1920's. The Leduc/Nisku solution arose in direct response to current socioeconomic conditions. The first test of 'Best Practices' is for innovation and creativity; today's 'Best Practices' will be redundant tomorrow.

2. Functions impacted by 'Best Practices' are raised to a new level. The sum of the parts becomes greater than the whole. Examples of this are the EDA's database, which produced an intellectual property, and the marketing program, which created an international presence and recognition out of all proportion to its resources.

3. 'Best Practices' becomes infectious, first on a local, then a regional basis. The involvement of the community grows, along with its pride and sense of achievement. In this way the attitude, standards and recognition became common property. Perhaps more than anything else, it becomes a healing process developing cooperation, unity and, above all, trust.

4. Holistic economic development recognizes that community growth occurs in many different ways. It has a high moral and ethical standard and pays special attention to developing the soft infrastructure, the spirit and will of the community as a whole. Only by harnessing and focusing the total human energy of a community can extraordinary achievements be realized. In practice it is, of course, the principal means by which the economic and social climate is created, thereby encouraging physical development to occur. 
Adopting 'Best Practices' is undertaking a work in progress; it is never finished. In every function of the organization, every program, process and service, innovation and creativity is employed to lift what is already good to outstanding, what is usual to exceptional and what is satisfactory to legendary. 'Best Practices' is achieved when the corporate attitude reaches beyond the bounds of the organization, when the sphere of its activities extends far beyond accepted limits and the impact of its service is out of all proportion to the core resources available. In this rapidly changing global village it is the way to maintain our self-respect and, perhaps, the only way to maintain our competitive advantage!

\section{Author's biography}

John Barnard is Executive Director of the Leduc/Nisku Economic Development Authority. John has a Certificate and Diploma in Economic Development from the University of Waterloo Economic Development Program. He has been directly involved in economic development for more than twenty years. John has produced and hosted forums, public meetings, workshops and conferences on energy, transportation, tourism, growth alternatives and economic trends. He has promoted the development of holistic economic development and urban planning concepts and strategies to re-invent healthy communities. He is the architect of the "People in Partnership" concept, maximizing community human resources to drive community economic development initiatives.

In 1996 John was voted Economic Developer of the Year by the Economic Developers Association of Alberta and in 1997 he was voted Economic Developer of Canada by the Economic Development Association of Canada (EDAC).

\section{Bibliography}

Apps, Jerold, Leadership for the Emerging Age, Jossey - Bass, 1994.

Argyris,Chris, Knowledge for Action: A guide to Overcoming Barriers to Organizational Change, Jossey - Bass, 1993.

Barrett, Frank J., "Creating Appreciative Learning Cultures”, Organizational Dynamics, Autumn, 1995.

Bennis, Warren, Parikh Jagdish and Ronnie Lessem,, Beyond Leadership, Blackewell Business, 1994. 
Burke, James, Connections, Macmillan, London, 1978.

Capra, Fritjof, The Tao of Physic, Sand, 1992.

Conner, Dennis, The Art of Winning, St. Martin's Press, 1989.

De Geus, Arie, The Living Company, Harvard Business School Press, 1997.

Fritz, Robert, The Path of Least Resistance, Ballantine Books, 1989.

Ogden, Frank, The Last Book You Will Ever Read, Macfarlane, Walter and Ross, 1993.

Paquet, Gilles, The Policy Process: Challenges and Responses, University of Ottawa.

Pedler, Mike, John Burgoyne and Tom Boydell, The Learning Company: A Strategy for

Sustainable Development, McGraw - Hill, 1991.

Secretan, Lance H.K., Reclaiming Higher Ground, Creating Organizations that Inspire the Soul, Macmillan, Canada, 1996.

Senge, Peter, The Fifth Discipline: The Art and Practice of the Learning Organization, Currency, Doubleday, 1994.

U.K. Department of Trade and Industry. http://www.dti.gov.uk.hbp/

Watkins, Karen E. and Victoria J. Marsick, Sculpting the Learning Organization: Lessons in the Art and Science of Systemic Change, Jossey - Bass, 1993. 